\title{
Improving the Stability of An Interconnected Power System Using Genetic Eigenvalue Technique
}

\author{
UGWU K.I ${ }^{1}$ OKAFOR E. N. $\mathrm{C}^{2} . \quad$ Alor M. $\mathrm{O}^{1}$ \\ 1. Department of Electrical Electronic Engineering, \\ Enugu State University of Science \& technology (ESUT), Enugu, Nigeria \\ 2: Federal University of Technology (FUTO), Owerri, Nigeria
}

\begin{abstract}
Improving the power stability of an interconnected Nigerian $330 \mathrm{KV} 48$ bus power system was developed using Genetic Eigenvalue Technique to mitigate the challenges of proper placement of power system stabilizer due to its highly dynamic and nonlinear nature. In order to eliminate load losses, equipment malfunctioning, and other quality issues, unnecessary tripping and cascaded failures in system network, power system stabilizers are installed to improve system stability. The operational and process data of $330 \mathrm{KV}$ power system grid network, cable distance meter (CDM-75), Transmission line calculator (AWR version) were sampled at Transmission Company of Nigeria Osogbo, Osun State of Nigeria. The Genetic Eigenvalue technique was used to generate eigenvalues, damping ratios and participation factors for proper placement of PSS (Power System Stabilizers) to mitigate the effect of transmission line and power plant outage contingencies. The PSSs were placed using Genetic Eigenvalue Analysis technique performed better than PSS placed based on conventional Arnoldi eigenvalue technique. The simulation results for base case voltage profile and for the trajectories of the impact of contingencies were plotted on the MATLAB/SUMULINK environment. From the output plots, the percentage of voltage instability suppression time improvement of Genetic technique over Arnoldi is 51.86\%. Oscillation suppression at generator 1, is $74 \%$, and that of generator 3 is $79 \%$, and finally at generator 5 is $76.98 \%$. PSS placed on Nigerian 330KV 48 bus plant and transmission line of an interconnected power system case study power system based on genetic analysis suppressed voltage oscillation faster compared to the time it took the PSS based on the conventional Arnoldi eigenvalue analysis technique.
\end{abstract}

Keywords: Power Stability- Genetic Eigenvalue, ArnoldiEigenvalue, PSS.

DOI: $10.7176 /$ JETP/11-1-03

Publication date: January $31^{\text {st }} 2021$

\section{Introduction}

System stability depends on the existence of both components of torque for each of the synchronous machines. Lack of sufficient synchronizing torque results in a periodic or non-oscillatory instability, whereas lack of damping torque results in oscillatory instability. For convenience in analysis and for gaining useful insight into the nature of stability problems, it is useful to characterize rotor angle stability in terms of the following two subcategories: small disturbance and global problems. However, Small-disturbance (or small-signal) rotor angle stability is concerned with the ability of the power system to maintain synchronism under small disturbances. The disturbances are considered to be sufficiently small that linearization of system equations is permissible for purposes of analysis [10]. Again global problems are caused by interactions among large groups of generators and have widespread effects. They involve oscillations of a group of generators in one area swinging against a group of generators in another area. Such oscillations are called inter-area mode oscillations. Their characteristics are very complex and significantly differ from those of local plant mode oscillations. Load characteristics, in particular, have a major effect on the stability of inter-area modes [9]. However, if power system is perturbed, the equilibrium is upset, resulting in acceleration or deceleration of the rotors of the machines according to the laws of motion of a rotating body. If one generator temporarily runs faster than another, the angular position of its rotor relative to that of the slower machine will advance. The resulting angular difference transfers part of the load from the slow machine to the fast machine, depending on the power-angle relationship. This tends to reduce the speed difference and hence the angular separation. The power-angle relationship is highly nonlinear. Beyond a certain limit, an increase in angular separation is accompanied by a decrease in power transfer such that the angular separation is increased further. Instability results if the system cannot absorb the kinetic energy corresponding to these rotor speed differences. For any given situation, the stability of the system depends on whether or not the deviations in angular positions of the rotors result in sufficient restoring torques.

\section{Review of the related works}

The study of eigenvalue changesdue to the single PSS installation at different units to determine the best PSS installment location was observed [1]. However, this work took a different approach by modeling the effect of PSS installation with an addition of a damping term to the equation of motion. The best PSS placement led to the most damped system. 
The methods outlined for PSS placement are sequential and can take into account the presence of PSSs that were already installed [9]. However, sequential placement does not always determine the best multiple PSS placements because placement order can affect the results. These methods require eigenvalue calculations after PSS installation at each generator.

A method was developed that save computation time by computing eigenvalue sensitivities to approximate the post-PSS-installed eigenvalues [9]. A pioneering work on eigenvalue sensitivities applied to power systems was done by They derived the Eigenvalue sensitivities to a power system parameter.

A developed way to calculate the eigenvalue sensitivities [2] to the closure of the open-loop system by installation of an ideal PSS. These sensitivities were computed with matrix residues of the open loop system while (8) used the same idea as [2] but proposed an improved algorithm that could be easily used with a large-scale system.

The study done by [5] on eigenvalue sensitivities were also used by to tune the PSS after installation showed that the eigenvalue sensitivities of an open-loop system due to installation of a static PSS are equal to the openloop residues. These sensitivities were used to tune the PSS but were not used to determine PSS placement. Similarly to [9] grouped the generators to determine a site of PSS installation. Ostojic, traced the origins of the electromechanical modes to one or a group of generators by looking at their aggregate momentum as shown in [5]. In the studied case, one generator from each group was chosen for PSS installation. However, the number and choice of generators for PSS installation was arbitrary.

The work of [10], by the papers discussed, shows that residues are commonly used to determine PSS installation sites. Another popular method is based on PFs (Participation Factors). A PF is a measure of the relative participation of a state in a mode and a mode in a state. Thus, it shows which machine and particular state greatly affects an eigenvalue of interest. For a given mode to be damped, the machine whose state participates the most in the mode should be installed with a PSS.

The work of [3] minimized the sum of PSS transfer functions weighted by their machine bases to determine PSS placement. The optimization problem was constrained by having to shift the eigenvalues to the stable region and by limits of the PSS parameters. This method both determined PSS placement and computed the PSS parameters. The optimization problem was solved for the shift in the eigenvalues by using a derived equation for eigenvalue sensitivities. This formulation was also used by [4] to determine PSS installation sites.

The work of (7) on optimization problem was also formulated to determine PSS placement. The objective was to minimize the PSS control gains with constraints to move the unstable eigenvalues to the stable region while not changing the stable eigenvalues. This approach assumed that PSSs were installed at every machine. Those with relatively higher gains solved for by the optimization problem were chosen for PSS installation. This method looked at the closed loop system, but minimization of the number of PSSs was not included in the constraints or the cost function. This method put the additional constraint of not moving the stable eigenvalues; a less restrictive constraint would put all the eigenvalues in the stable region. Other approaches to determine the best locations for PSS installations have been investigated

\section{Methodology}

The Nigerian $330 \mathrm{KV}$, 48-bus system was modeled as the case study power system for the simulation experiment, to validate the stability analysis technique and the proposed power system damping controller. The MATLAB Simulink environment is used for the modeling and development of the case study interconnected power system damping controller and for programming the genetic-eigenvalue stability analyzer. For the testing and evaluation of the solution, different transient disturbances were simulated and injected into the MATLAB model of the case study power grid to investigate the performance of the solution. Simulations are carried out to determine the effect on the power system angle stability, voltage stability and frequency stability of the case study of power system. The stability of the 48-bus case study interconnected power grid is evaluated with the power system damping controller and the stability analyzer on the one hand, and without the damping controller and the hybrid stability analyzer on the other hand. The model of the stability analyzer and the power system damping controller and simulation of case study power system using MATLAB is developed 


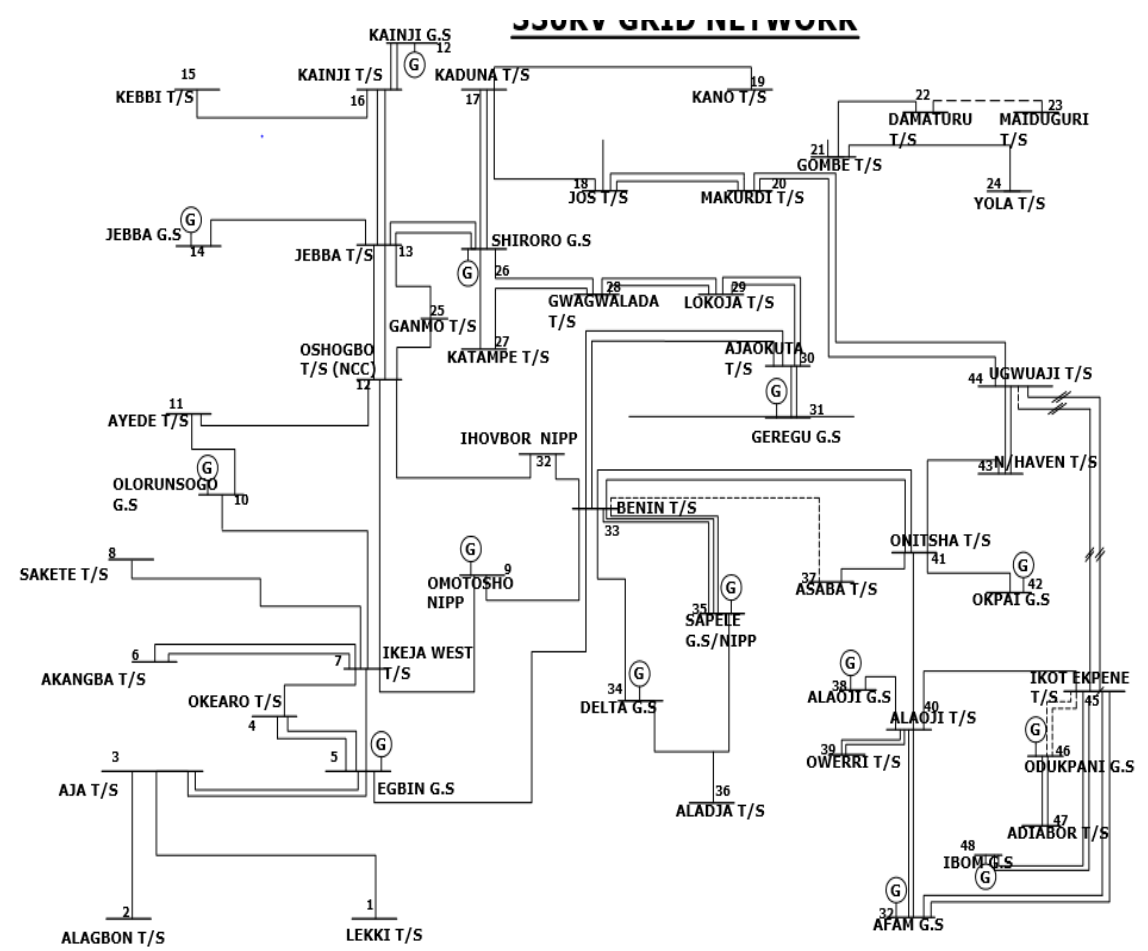

Figure 1: Line Diagram of Nigerian 330KV 48-Bus

The Nigerian 330KV, 48-bus was modeled using MATLAB Simulink tool box. This shows 48-bus for further simulations on the network as shown on fig 1 . System data for the existing 48 -bus Nigeria $330 \mathrm{kV}$ power networks obtained from Power Transmission Company of Nigeria (TCN), were used as input data which provided the values of series impedances, admittances of the transmission lines, transformer ratings and impedances required for the power/load flow study. These parameters were modeled and simulated in MATLAB/SIMULINK power system analysis using Newton-Raphson power flow algorithm.

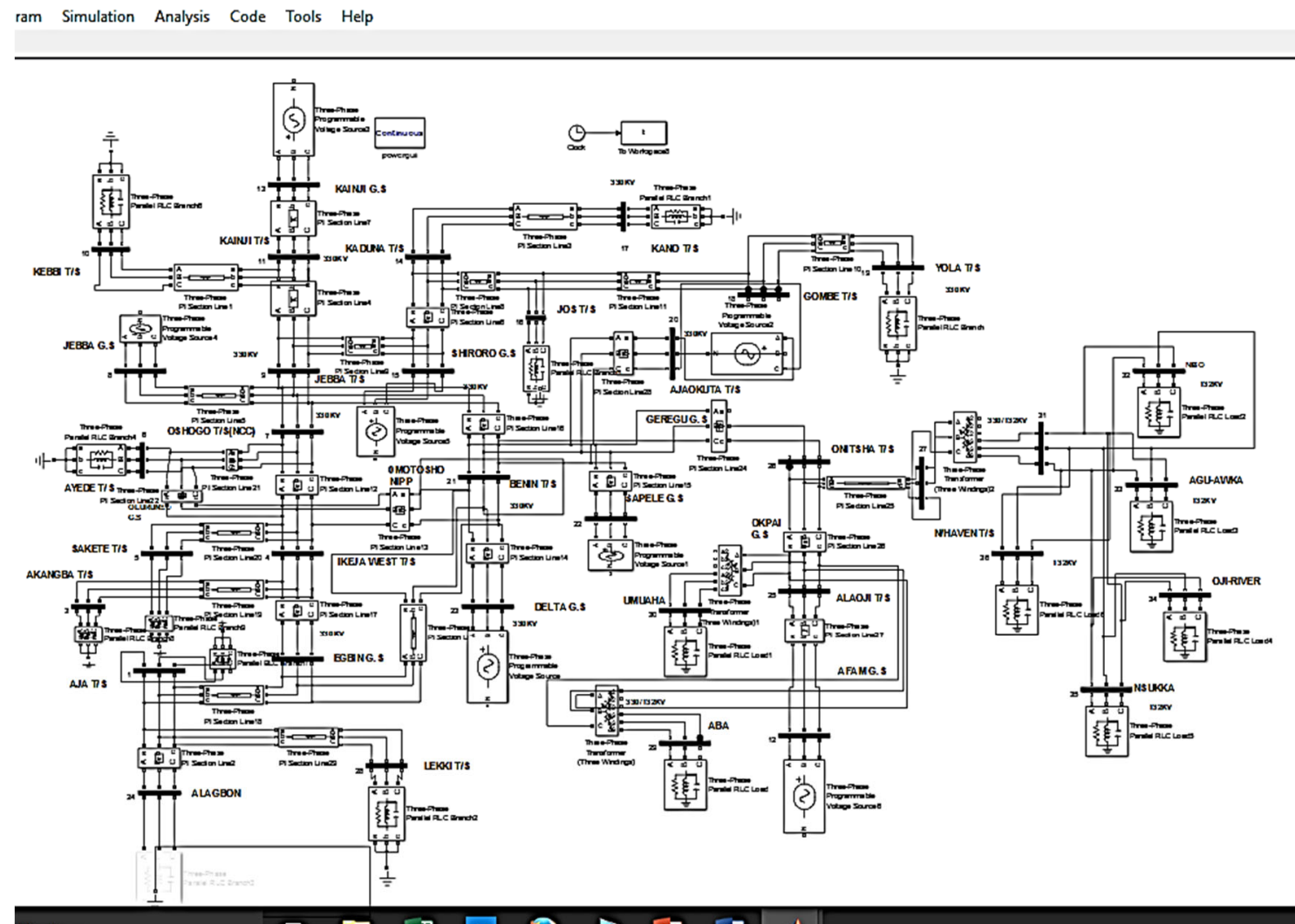


The Simulink model of Nigerian 330KV, 48-bus interconnected system was developed for load flow studies, to see the base case voltage profile of the network and for further simulations on the implementation of genetic eigenvalue algorithm

\section{Mathematical Model of Power Flow and Eigenvalue Analysis}

Power system matrices are required for the stability analyses of genetic eigenvalue analysis program, hence the mathematical model were derived as shown

$$
I=Y V=\frac{S *}{V *}
$$

Where

I $\quad=\quad$ Modal current injection matrix

$\mathrm{Y} \quad=\quad$ System modal admittance

$\mathrm{V} \quad=\quad$ Unknown complex mode voltage vector

$\mathrm{S} \quad=\quad$ Apparent power modal injection vector representing specified load and generation of nodes.

Where

$$
\mathrm{S}=\mathrm{P}+\mathrm{JQ}
$$

The using Newton-Raphson method from (3), the equation for node $\mathrm{K}$ (bus $\mathrm{K}$ ) is written as:

$$
\begin{aligned}
& I_{K} \sum_{m=1}^{n} Y_{K M} V_{m} \\
& P_{K}+J Q_{k}=V_{K} I_{K}=V_{K} \sum_{m=1}^{n} Y_{K M} V_{m}
\end{aligned}
$$

Where

$$
\begin{aligned}
& \mathrm{M}=1,2 \ldots \ldots \ldots \mathrm{n} \\
& \mathrm{n}=\text { number of buses } \\
& V_{k} \text { is the voltage of the } \mathrm{K} \text { bus }
\end{aligned}
$$

$Y_{K M}$ is the element of the admittance bus equating the real and imaginary parts

$$
\begin{aligned}
& P_{K}=K_{e}\left(V_{K}\left(\sum_{m=1}^{n} Y^{*}{ }_{K M} V^{*}{ }_{K}\right)\right) \\
& Q_{K}=I_{M}\left(V_{K}\left(\sum_{m=1}^{n} Y^{*}{ }_{K M} V^{*}{ }_{K}\right)\right)
\end{aligned}
$$

Where

$P_{K}$ is the real power

$Q_{K}$ is the reactive power with the following notation:

$V_{K}=\left|V_{K}\right| e^{j q_{k}}, V_{M}=\left|V_{m}\right| e^{j q_{m}}, Y_{K M^{2}}\left|Y_{K M}\right| e^{j t}$

Where

$\left|V_{K}\right|$ is the magnitude of the voltage

$\delta_{k}$ is the angle of the voltage

$\delta_{k m}$ is the load angle

Substituting for $V_{k}, V_{m}$, and $Y_{k m}$ in equation

$P_{K}+J Q_{K}=\left|V_{K}\right| e^{j d_{k}} \sum_{m=1}^{n}\left|V_{k}\right|\left|Y_{K M}\right| e^{j q_{k m}}$

$P_{K}+J Q_{K}=\left|V_{K}\right| \sum_{m=1}^{n}\left|V_{k}\right|\left|Y_{K M}\right| e^{j\left(\delta_{k}-\delta_{m}=\delta_{k m}\right)}$ 
Or

$P_{K}+J Q_{K}=\left|V_{K}\right| \sum_{m=1}^{n}\left|V_{k}\right|\left|Y_{K M}\right|<\left(\delta_{k}-\delta_{k}-\delta_{k m}\right)$

Or

$+J Q_{K}=\left|V_{K}\right| \sum_{m=1}^{n}\left|V_{k}\right| Y_{K M} \mid\left(\cos \oint_{k}-\delta_{m}-Q_{k m}\right)+J \sin \left(\delta_{k}-\delta_{m}-Q_{k m}\right)$

Separating the real and imaginary parts of above equations to get real and reactive power

$P_{K}=\left|V_{K}\right| \sum_{m=1}^{n}\left|V_{k}\right|\left|Y_{K M}\right| \cos \left(\delta_{k}-\delta_{m}-Q_{k m}\right)$

$Q_{K}=\left|V_{K}\right| \sum_{m=1}^{n}\left|V_{k}\right|\left|Y_{K M}\right| \sin \left(\delta_{k}-\delta_{m}-Q_{k m}\right)$

The mismatch power at bus $\mathrm{K}$ is given by:

$\Delta P_{K}=P_{K}^{s c h}-P_{K}$

$\Delta \mathrm{Q}_{K}=Q_{K}^{\text {sch }}-Q_{K}$

The $P_{K}$ and $Q_{K}$ are calculated from equations (3.13) and (3.14)

The Newton - Raphson method solves the partitioned matrix equation:

$\left[\frac{\Delta P}{\Delta Q}\right]=J\left[\frac{\Delta Q}{\Delta V}\right]$

Where

$\Delta P$ and $\Delta Q=$ mismatch active and reactive power vectors

$\Delta V$ and $\Delta Q=$ unknown voltage magnitude and angle correction vectors

$\mathrm{J}=$ Jacobean matrix of partial derivative terms

The eigenvalues associated with a mode of voltage and reactive power variation can provide a relative measure of proximity to voltage instability. Then, the participation factor can be used to find out the weak nodes or buses in the system.

Equation (3.15) can be written as:

$\left[\frac{\Delta P}{\Delta Q}\right]=\left[\begin{array}{ll}\frac{J_{11}}{J_{21}} & \frac{J_{12}}{J_{22}}\end{array}\right]\left[\frac{\Delta Q}{\Delta V}\right]$

By letting $\Delta P=O_{\text {in Equation (3.18) }}$

$\Delta P=O=J_{11} \Delta \theta+J_{12} \Delta V$

Where

$$
\begin{aligned}
& \Delta \theta=-J_{11}^{-1} J_{12} \Delta V \\
& \Delta \theta=-J_{21} \Delta \theta+J_{22} \Delta V
\end{aligned}
$$

Subtracting equation (17) in equation (21)

$$
\Delta \theta=-J_{R} \Delta V
$$

Where

$$
J_{R}=\left[J_{22}-J_{21} J_{11}^{-1} J_{12}\right]
$$

$J_{R}$ is the reduced jacobian matrix of the system

Equation (13) can be written as 


$$
\Delta V=J_{R}^{-1} \Delta Q
$$

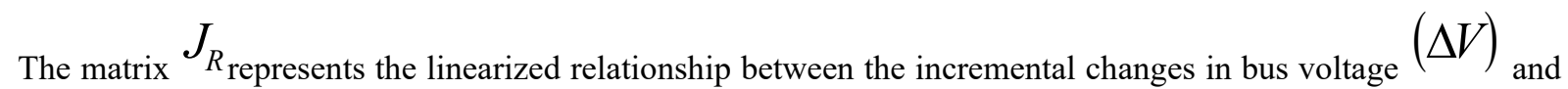
bus reactive power injection $(\Delta Q)$. It is well known that the system voltage is affected by both real and reactive power variations. In order to focus the study of the reactive demand and supply problem of the system as well as minimize computations effort by reducing dimension of the computation effort by reducing dimensions of the Jacobean Matrix J the real power $(\Delta P=O)$ and angle part from the system his equation (3.13) are eliminated.. The eigenvalues and Eigen-vectors of the reduced order Jacobean matrix $\left(J_{R}\right)$ are used for the power system stability characterized analysis. Instability can be detected by identifying modes of the eigenvalues matrix $\left(J_{R}\right)$. The magnitude of the eigenvalues provides a relative measure of proximity to instability. The eigenvectors on the other hand present information related to the mechanism of loss of voltage stability.

Modal analysis of $\left(J_{R}\right)$ results in the following

$$
\left(J_{R}\right)=\tau \phi \xi_{\text {igl }}
$$

\section{Notation used in the flow chart:}

$A=\left(J_{R}\right)$ is the system matrix, based on the model of the power system

$H$ is matrix having orthonormal columns

$V$ is matrix having orthonormal columns (can also be an invariant sup space of matrix A)

$x, f$ are the Ritz vectors

$\lambda$ is the eigenvalues

$\sigma$ is a shift

I is the identity matrix

$$
\begin{aligned}
\xi_{\text {eigl }} & =\text { left eigenvector matrix of }\left(J_{R}\right) \\
\mathrm{X} & =\text { diagonal eigenvalue matrix of }\left(J_{R}\right)
\end{aligned}
$$

Equation (3.22) can be written as:

$$
J_{R}^{-1}=\phi \xi_{\text {eigl }}
$$

The appropriate definition and determination as to which modes or buses participates in the selected mode become very important. The participation factor is computed to identify the weakest nodes or lead buses that are making significant contribution to the selected modes.

The participation factor is given by

$$
X_{i}=\frac{\sum \phi_{i} \xi_{e i \lambda l}}{\lambda_{i}} \Delta Q
$$

Where $\lambda_{i}$ is the $i^{\text {th }}$ eigenvalue, $\phi_{i}$ is the column right eigenvector and is the $i^{\text {th }}$ column right eigenvector and $\xi_{\text {ei } i l}$ is the $i^{\text {th }}$ row left eigenvector of matrix $\left(J_{R}\right)$

Each eigenvalue and corresponding right and left eigenvectors $\phi_{i}$ and $\xi_{e i \lambda l}$, defines the $i^{\text {th }}$ modes of the system. 


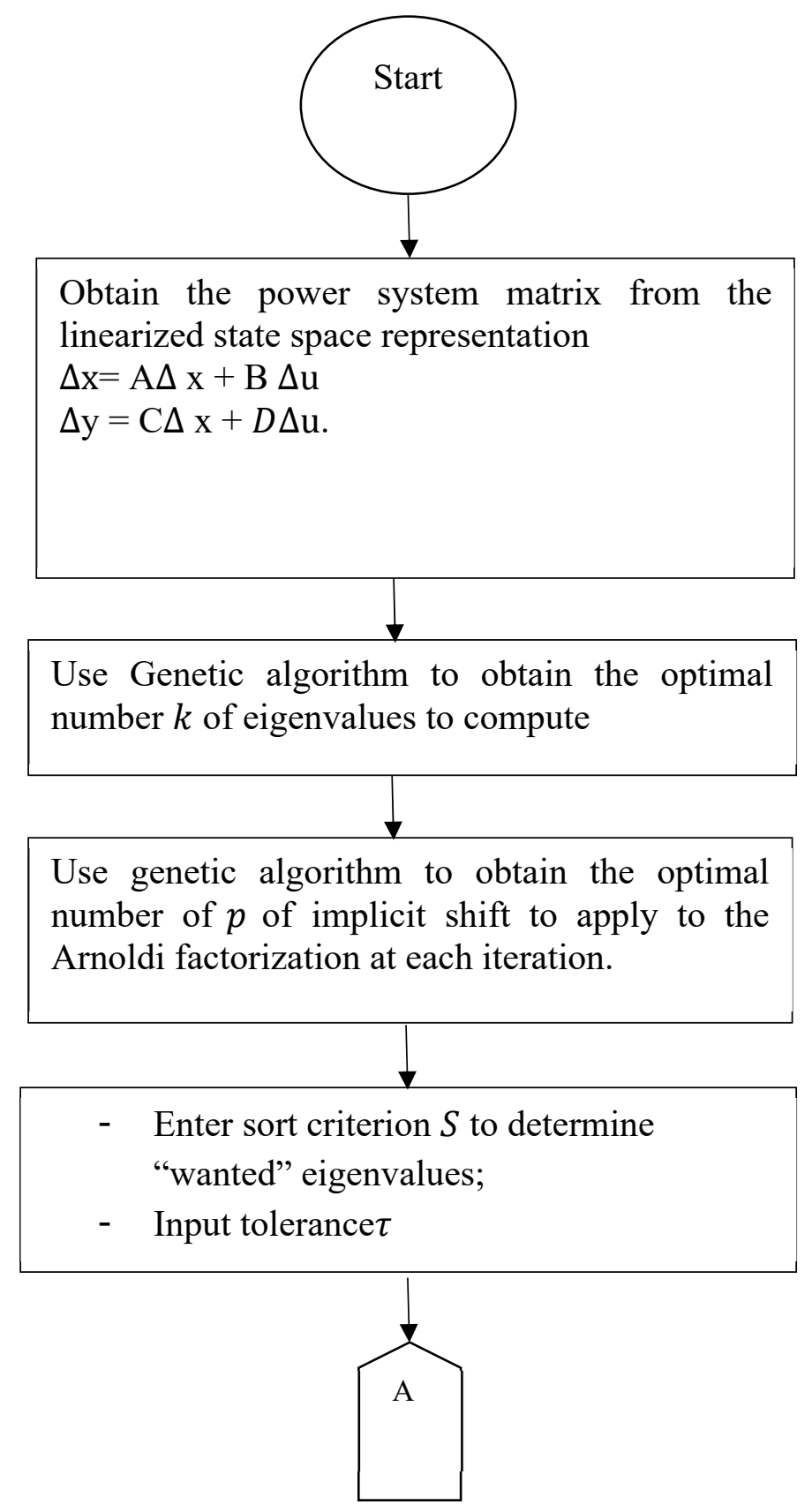




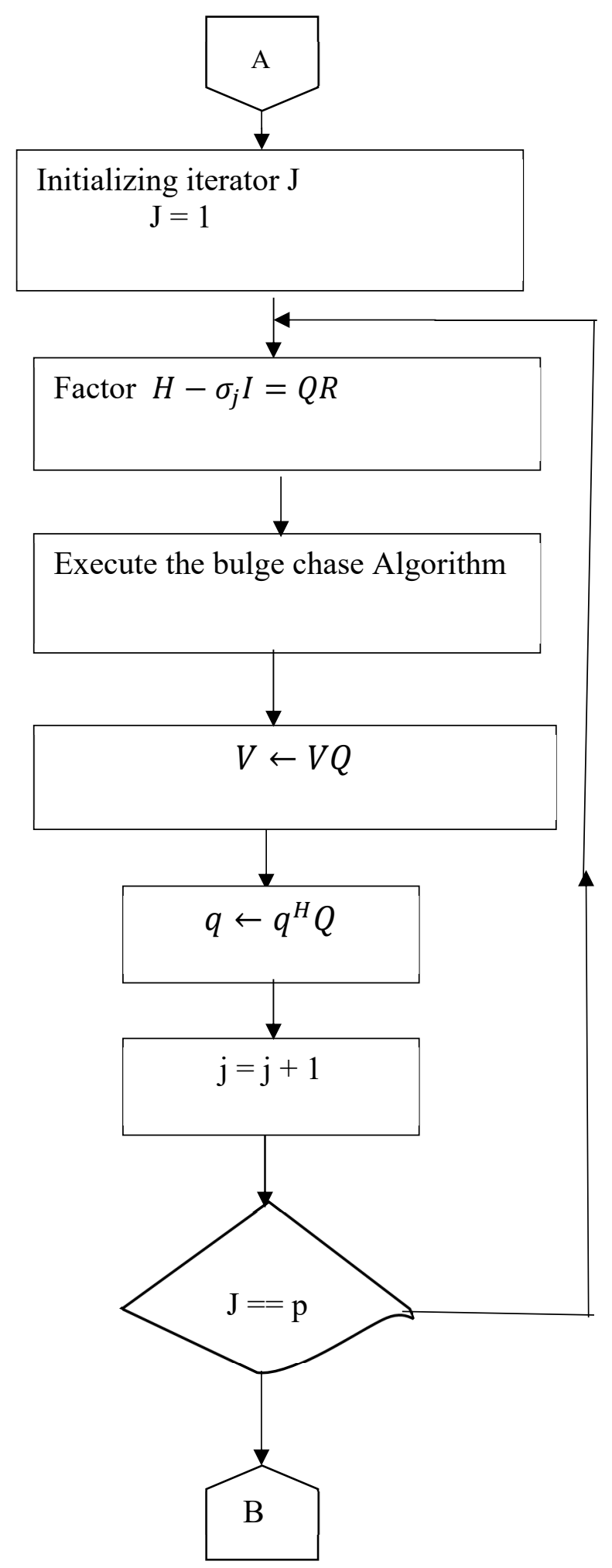

Fig 3: Flow Chart for Genetic Eigenvalue programming

The flow chart for the implementation of the Genetic eigenvalue algorithm programming was developed as shown in fig 3 contains an arranged parameters for simulation and generation of eigenvalues, and computation of participation factors and damping ratios of the Nigerian 330KV 48-Bus network from the network Simulink of figure 3. The genetic eigenvalue stability analysis program, the eigenvalues of the network are extracted, participation factors and damping ratios of the generators were equally computed by the program hence the stabilizers are placed on the generators based on their participation factors and damping ratios as computed from their eigenvalues. 


\section{Simulations}

The base data for this paper are system parameters of Nigerian 330KV 48-bus system from Transmission Company of Nigeria. There are 14 synchronous generators in the system. The base voltage is 330KVA and 100MVA. The generator, line and bus parameters used for simulation and computations are listed in table 1.

Table 1: The Generator Parameters

\begin{tabular}{|l|l|l|l|l|}
\hline S/No & Generator Station & Generation & Rated Voltage & Voltage P.U \\
\hline 1 & Kainji & $292 \mathrm{Mw}$ & $332 \mathrm{KV}$ & 1.0060 \\
\hline 2 & Jebba & $404 \mathrm{Mw}$ & $312 \mathrm{KV}$ & 0.9455 \\
\hline 3 & Shiroro & $450 \mathrm{Mw}$ & $320 \mathrm{KV}$ & 0.9697 \\
\hline 4 & Egbini & $611 \mathrm{Mw}$ & $335 \mathrm{KV}$ & 1.0151 \\
\hline 5 & Sapele & $68 \mathrm{Mw}$ & $332 \mathrm{KV}$ & 1.0060 \\
\hline 6 & Delta & $470 \mathrm{Mw}$ & $318 \mathrm{KV}$ & 0.9636 \\
\hline 7 & Geregu & $144 \mathrm{Mw}$ & $319 \mathrm{KV}$ & 0.9677 \\
\hline 8 & Omotosho & $187.5 \mathrm{Mw}$ & $305 \mathrm{KV}$ & 0.9242 \\
\hline 9 & Olominsogo gas & $163.6 \mathrm{Mw}$ & $300 \mathrm{KV}$ & 0.9090 \\
\hline 10 & Geregu NIPP & $150 \mathrm{Mw}$ & $331 \mathrm{KV}$ & 1.0030 \\
\hline 11 & Sapele NIPP & $113.1 \mathrm{Mw}$ & $320 \mathrm{KV}$ & 0.9692 \\
\hline 12 & Olorunsogo NIPP & $130.9 \mathrm{Mw}$ & $316 \mathrm{KV}$ & 09576 \\
\hline 13 & Omotosho NIPP & $228 \mathrm{Mw}$ & $347 \mathrm{KV}$ & 1.05151 \\
\hline 14 & Okapia & $363 \mathrm{Mw}$ & $331 \mathrm{KV}$ & 1.0030 \\
\hline
\end{tabular}

\section{Bus Parameter}

\section{System Details}

MVA Base $=100 \mathrm{MVA}$

System frequency $=50 \mathrm{~Hz}$

$2=$ Generator Bus (pv)

Bus Nominal Voltage $=330 \mathrm{KV}$

Bus Maximum Voltage $=330.5 \mathrm{kv}$

Table 2: Bus Parameters

\begin{tabular}{|c|c|c|c|c|c|c|c|}
\hline Bus No & $\stackrel{0}{E}$ & $\begin{array}{l}\mathrm{Max}-\mathrm{Vm}- \\
\mathrm{Pu}\end{array}$ & Min-Vm-Pu & Area & હ̃ & In-Service & Vn-KV \\
\hline 1 & 2 & 1.05 & 0.95 & 1 & 1 & True & $330 \mathrm{KV}$ \\
\hline 2 & 2 & 1.05 & 0.95 & 1 & 1 & True & $330 \mathrm{KV}$ \\
\hline 3 & 2 & 1.05 & 0.95 & 1 & 1 & True & $330 \mathrm{KV}$ \\
\hline 4 & 2 & 1.05 & 0.95 & 1 & 1 & True & $330 \mathrm{KV}$ \\
\hline 5 & 2 & 1.05 & 0.95 & 1 & 1 & True & $330 \mathrm{KV}$ \\
\hline 6 & 2 & 1.05 & 0.95 & 1 & 1 & True & $330 \mathrm{KV}$ \\
\hline 7 & 2 & 1.05 & 0.95 & 1 & 1 & True & $330 \mathrm{KV}$ \\
\hline 8 & 2 & 1.05 & 0.95 & 1 & 1 & True & $330 \mathrm{KV}$ \\
\hline 9 & 2 & 1.05 & 0.95 & 1 & 1 & True & $330 \mathrm{KV}$ \\
\hline 10 & 2 & 1.05 & 0.95 & 1 & 1 & True & $330 \mathrm{KV}$ \\
\hline 11 & 2 & 1.05 & 0.95 & 1 & 1 & True & $330 \mathrm{KV}$ \\
\hline 12 & 2 & 1.05 & 0.95 & 1 & 1 & True & $330 \mathrm{KV}$ \\
\hline 13 & 2 & 1.05 & 0.95 & 1 & 1 & True & $330 \mathrm{KV}$ \\
\hline 14 & 2 & 1.05 & 0.95 & 1 & 1 & True & $330 \mathrm{KV}$ \\
\hline 15 & 2 & 1.05 & 0.95 & 1 & 1 & True & $330 \mathrm{KV}$ \\
\hline 16 & 2 & 1.05 & 0.95 & 1 & 1 & True & $330 \mathrm{KV}$ \\
\hline 17 & 2 & 1.05 & 0.95 & 1 & 1 & True & $330 \mathrm{KV}$ \\
\hline 18 & 2 & 1.05 & 0.95 & 1 & 1 & True & $330 \mathrm{KV}$ \\
\hline 19 & 2 & 1.05 & 0.95 & 1 & 1 & True & $330 \mathrm{KV}$ \\
\hline 20 & 2 & 1.05 & 0.95 & 1 & 1 & True & $330 \mathrm{KV}$ \\
\hline 21 & 2 & 1.05 & 0.95 & 1 & 1 & True & $330 \mathrm{KV}$ \\
\hline 22 & 2 & 1.05 & 0.95 & 1 & 1 & True & $330 \mathrm{KV}$ \\
\hline 23 & 2 & 1.05 & 0.95 & 1 & 1 & True & $330 \mathrm{KV}$ \\
\hline 24 & 2 & 1.05 & 0.95 & 1 & 1 & True & $330 \mathrm{KV}$ \\
\hline
\end{tabular}

Type:

$1=$ Load Bus

$3=$ System Wiring Bus 


\begin{tabular}{|c|c|c|c|c|c|c|c|}
\hline Bus No & $\underset{F}{\stackrel{2}{*}}$ & $\begin{array}{l}\mathrm{Max}-\mathrm{Vm}- \\
\mathrm{Pu}\end{array}$ & Min-Vm-Pu & Area & ঠ̃ & In-Service & Vn-KV \\
\hline 25 & 2 & 1.05 & 0.95 & 1 & 1 & True & $330 \mathrm{KV}$ \\
\hline 26 & 2 & 1.05 & 0.95 & 1 & 1 & True & $330 \mathrm{KV}$ \\
\hline 27 & 2 & 1.05 & 0.95 & 1 & 1 & True & $330 \mathrm{KV}$ \\
\hline 28 & 2 & 1.05 & 0.95 & 1 & 1 & True & $330 \mathrm{KV}$ \\
\hline 29 & 2 & 1.05 & 0.95 & 1 & 1 & True & $330 \mathrm{KV}$ \\
\hline 30 & 2 & 1.05 & 0.95 & 1 & 1 & True & $330 \mathrm{KV}$ \\
\hline 31 & 2 & 1.05 & 0.95 & 1 & 1 & True & $330 \mathrm{KV}$ \\
\hline 32 & 2 & 1.05 & 0.95 & 1 & 1 & True & $330 \mathrm{KV}$ \\
\hline 33 & 2 & 1.05 & 0.95 & 1 & 1 & True & $330 \mathrm{KV}$ \\
\hline 34 & 2 & 1.05 & 0.95 & 1 & 1 & True & $330 \mathrm{KV}$ \\
\hline 35 & 2 & 1.05 & 0.95 & 1 & 1 & True & $330 \mathrm{KV}$ \\
\hline 36 & 2 & 1.05 & 0.95 & 1 & 1 & True & $330 \mathrm{KV}$ \\
\hline 37 & 2 & 1.05 & 0.95 & 1 & 1 & True & $330 \mathrm{KV}$ \\
\hline 38 & 2 & 1.05 & 0.95 & 1 & 1 & True & $330 \mathrm{KV}$ \\
\hline 39 & 2 & 1.05 & 0.95 & 1 & 1 & True & $330 \mathrm{KV}$ \\
\hline 40 & 2 & 1.05 & 0.95 & 1 & 1 & True & $330 \mathrm{KV}$ \\
\hline 41 & 2 & 1.05 & 0.95 & 1 & 1 & True & $330 \mathrm{KV}$ \\
\hline 42 & 2 & 1.05 & 0.95 & 1 & 1 & True & $330 \mathrm{KV}$ \\
\hline 43 & 2 & 1.05 & 0.95 & 1 & 1 & True & $330 \mathrm{KV}$ \\
\hline 44 & 2 & 1.05 & 0.95 & 1 & 1 & True & $330 \mathrm{KV}$ \\
\hline 45 & 2 & 1.05 & 0.95 & 1 & 1 & True & $330 \mathrm{KV}$ \\
\hline 46 & 2 & 1.05 & 0.95 & 1 & 1 & True & $330 \mathrm{KV}$ \\
\hline 47 & 2 & 1.05 & 0.95 & 1 & 1 & True & $330 \mathrm{KV}$ \\
\hline 48 & 2 & 1.05 & 0.95 & 1 & 1 & True & $330 \mathrm{KV}$ \\
\hline
\end{tabular}


Table 3: Load Flow Result for the Plot of the Profile of the Base Case Power System

\begin{tabular}{|c|c|c|c|c|c|}
\hline BUS & Voltage $(p, u)$ & Angle(rad) & $\begin{array}{c}P \\
\operatorname{gen}(p \cdot u)\end{array}$ & $\begin{array}{c}\mathrm{Q} \\
\operatorname{gen}(\mathrm{p} . \mathrm{u})\end{array}$ & $\begin{array}{c}P \\
\operatorname{load}(p . u)\end{array}$ \\
\hline 1 & 0.9604 & -0.03153 & $4.86 \mathrm{E}-14$ & $1.4 \mathrm{E}-12$ & 1.89 \\
\hline 2 & 0.9668 & -0.02274 & 2.4 & 1.251088 & 0 \\
\hline 3 & 0.9026 & -0.01048 & $1.15 \mathrm{E}-13$ & $4.33 \mathrm{E}-13$ & 4.5 \\
\hline 4 & 0.9702 & -0.0254 & $1.55 \mathrm{E}-15$ & $-9.4 \mathrm{E}-15$ & 1.95 \\
\hline 5 & 0.8436 & 0.087284 & 3.213 & 0.004826 & 0 \\
\hline 6 & 0.7858 & -0.00543 & $-1.1 \mathrm{E}-13$ & $-5.6 \mathrm{E}-13$ & 9.18 \\
\hline 7 & 0.9754 & 0.085714 & 0.8 & 0.583475 & 0 \\
\hline 8 & 0.9118 & -0.03631 & $4.09 \mathrm{E}-14$ & $9.21 \mathrm{E}-13$ & 1.545 \\
\hline 9 & 0.9546 & -0.08476 & 2.16 & 9.594193 & 1.545 \\
\hline 10 & 0.7598 & -0.10347 & $-1 \mathrm{E}-14$ & $-1.7 \mathrm{E}-13$ & 0 \\
\hline 11 & 0.7003 & -0.0065 & $8.08 \mathrm{E}-14$ & $-1.2 \mathrm{E}-13$ & 2.424 \\
\hline 12 & 0.9176 & 0.08684 & 1.928 & 0.753387 & 0 \\
\hline 13 & 0.9731 & 0.085158 & $2.71 \mathrm{E}-13$ & $1.98 \mathrm{E}-13$ & 2.292 \\
\hline 14 & 0.8760 & -0.07592 & 1.2 & -1.84677 & 0 \\
\hline 15 & 0.9055 & 0.085664 & $-7.3 \mathrm{E}-14$ & $-6.3 \mathrm{E}-14$ & 0 \\
\hline 16 & 0.7962 & -0.13836 & $-1.3 \mathrm{E}-13$ & $-1 \mathrm{E}-13$ & 1.146 \\
\hline 17 & 0.8338 & -0.03392 & $-3 \mathrm{E}-13$ & $-2.2 \mathrm{E}-13$ & 1.53 \\
\hline 18 & 0.9569 & -0.13756 & $-3.2 \mathrm{E}-14$ & $-2.4 \mathrm{E}-14$ & 0 \\
\hline 19 & 0.9506 & -0.03113 & 1.76 & 5.189297 & 1.89 \\
\hline 20 & 0.7517 & -0.07522 & $2.35 \mathrm{E}-13$ & $9.63 \mathrm{E}-14$ & 0 \\
\hline 21 & 0.7540 & 0.085614 & $-2.9 \mathrm{E}-13$ & $1.91 \mathrm{E}-13$ & 2.292 \\
\hline 22 & 0.9535 & -0.00585 & $-9.4 \mathrm{E}-14$ & $1.06 \mathrm{E}-12$ & 2.7 \\
\hline 23 & 0.7257 & -0.02394 & $-4.5 \mathrm{E}-13$ & $-4.6 \mathrm{E}-14$ & 0 \\
\hline 24 & 0.9691 & $-0.02655 \mid$ & $-4.6 \mathrm{E}-14$ & $-3.2 \mathrm{E}-13$ & 1.146 \\
\hline 25 & 0.8899 & -0.00946 & $-1.3 \mathrm{E}-13$ & $-6.3 \mathrm{E}-13$ & 3.6 \\
\hline 26 & 0.9436 & -0.02736 & 1.125 & 0.236856 & 0 \\
\hline 27 & 0.9621 & 0.083392 & $-2.2 \mathrm{E}-13$ & $-1.3 \mathrm{E}-13$ & 0 \\
\hline 28 & 0.8587 & -0.06639 & $9.88 \mathrm{E}-16$ & $2.81 \mathrm{E}-14$ & 0 \\
\hline 29 & 0.7720 & -0.10593 & $7.99 \mathrm{E}-15$ & $7.53 \mathrm{E}-14$ & 1.275 \\
\hline 30 & 0.9754 & -0.0242 & $-2.4 \mathrm{E}-14$ & $-1.7 \mathrm{E}-13$ & 1.95 \\
\hline 31 & 0.7431 & -0.02572 & $-1 \mathrm{E}-14$ & $-1.7 \mathrm{E}-13$ & 0.73725 \\
\hline 32 & 0.7991 & -0.02977 & $-2.7 \mathrm{E}-15$ & $-3.1 \mathrm{E}-14$ & 1.617 \\
\hline 33 & 0.9032 & -0.11249 & $7.24 \mathrm{E}-15$ & $-2.9 \mathrm{E}-14$ & 0 \\
\hline 34 & 0.8465 & -0.02361 & $7.82 \mathrm{E}-13$ & $5.08 \mathrm{E}-13$ & 1.2471 \\
\hline 35 & 0.9529 & -0.13943 & $-4.3 \mathrm{E}-14$ & $-3 \mathrm{E}-14$ & 0.615 \\
\hline 36 & 0.9801 & -0.02648 & 2.4 & 0.104634 & 0 \\
\hline 37 & 0.9529 & 0 & 46.0197 & 9.032308 & 0 \\
\hline 38 & 0.9853 & -0.14123 & $-1.9 \mathrm{E}-14$ & $2.61 \mathrm{E}-14$ & 0.573 \\
\hline 39 & 0.9639 & -0.03703 & $-5.1 \mathrm{E}-15$ & $-1.2 \mathrm{E}-14$ & 1.545 \\
\hline 40 & 0.9766 & -0.02195 & 2.4 & -0.33846 & 0 \\
\hline 41 & 0.9303 & -0.13818 & $4.2 \mathrm{E}-14$ & $1.86 \mathrm{E}-13$ & 1.548 \\
\hline 42 & 0.9673 & -0.04831 & $-6 \mathrm{E}-15$ & $1.44 \mathrm{E}-14$ & 1.8609 \\
\hline 43 & 0.9147 & -0.14204 & 1.104 & 1.672078 & 0 \\
\hline 44 & 0.9598 & -0.03259 & $1.42 \mathrm{E}-14$ & $8.36 \mathrm{E}-14$ & 0.91725 \\
\hline 45 & 0.8477 & -0.01242 & 4.56 & 0.542995 & 0.6225 \\
\hline 46 & 0.9587 & -0.01106 & $-6.5 \mathrm{E}-14$ & $3.14 \mathrm{E}-13$ & 6.29 \\
\hline 47 & 0.8205 & -0.53696 & $3.29 \mathrm{E}-13$ & $3.79 \mathrm{E}-14$ & 1.65 \\
\hline 48 & 0.9014 & -0.02617 & 4.416 & 0.667066 & 0.765 \\
\hline
\end{tabular}




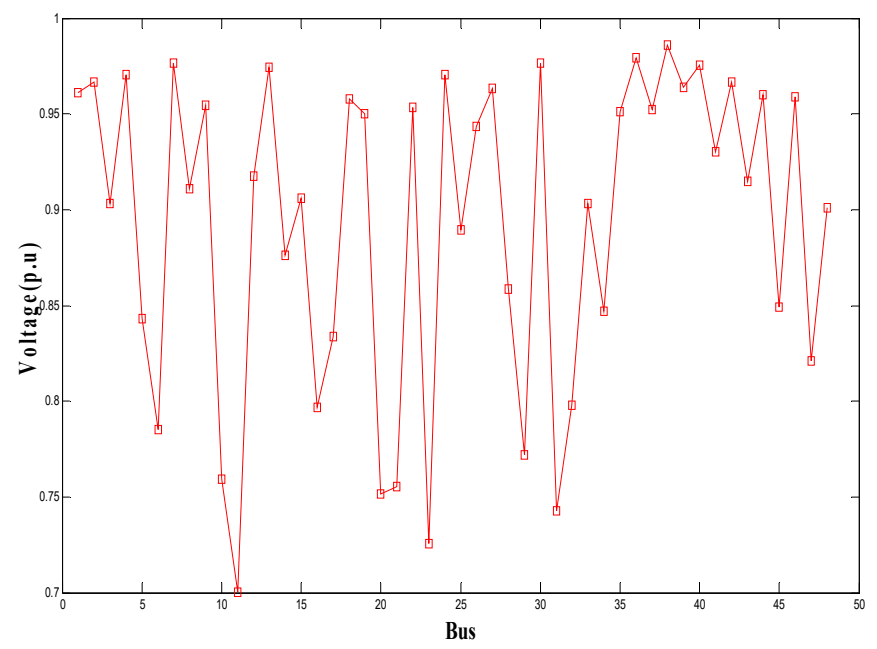

Fig. 4: Voltage Profile of the Base Case of Nigerian 330KV Power System

From the load flow result, it can be seen that 27 buses are below the 5\% voltage drop limit. This shows substantial weakness in the power system under investigation which might lead to instability.. However, this does not give much information regarding the distribution of instabilities in the system. Hence further simulations were carried out using the hybrid of Genetic and Arnoldi Eigenvalue analysis technique to find the eigenvalues, the damping ratios and the participation factors in the power system for proper placement of Power System Stabilizers Result of Pflw solution on outage of transmission line without stabilizer

Table 4: Eigenvalue and Damping Ratio of the case Study Power System Buses during the Outage of the Transmission Line between Bus 31 and 29.

\begin{tabular}{|c|c|c|c|}
\hline S/No. & Bus No. & Eigen value $(\lambda)$ & Damping Ratio(s) \\
\hline 1 & 1 & $0.1123 \pm \mathrm{j} 7.0876$ & 1.0675 \\
\hline 2 & 2 & $0.0448 \pm \mathrm{j} 4.0309$ & -0.0110 \\
\hline 3 & 3 & $0.5526 \pm \mathrm{j} 7.3025$ & 0.02437 \\
\hline 4 & 4 & $0.0547 \pm \mathrm{j} 3.2853$ & 0.0135 \\
\hline 5 & 5 & $0.0413 \pm \mathrm{j} 3.3227$ & -0.0124 \\
\hline 6 & 6 & $-0.5248 \pm \mathrm{j} 3.8483$ & 0.1035 \\
\hline 7 & 7 & $0.0014 \pm \mathrm{j} 2.5144$ & -0.0057 \\
\hline 8 & 8 & $0.1912 \pm \mathrm{j} 5.808$ & -0.0332 \\
\hline 9 & 9 & $0.1953 \pm \mathrm{j} 5.716$ & -0.0348 \\
\hline 10 & 10 & $0.088 \pm \mathrm{j} 4.002$ & -0.022 \\
\hline 11 & 11 & $0.4302 \pm \mathrm{j} 3.6798$ & -0.4067 \\
\hline 12 & 12 & $0.0281 \pm \mathrm{j} 2.0154$ & -0.0013 \\
\hline 13 & 13 & $-0.1212 \pm \mathrm{j} 3.7982$ & -0.0324 \\
\hline 14 & 14 & $0.0953 \pm \mathrm{j} 3.3835$ & -0.0256 \\
\hline 15 & 15 & $0.0883 \pm \mathrm{j} 4.0012$ & -0.0225 \\
\hline 16 & 16 & $0.0335 \pm \mathrm{j} 6.852$ & -0.005 \\
\hline 17 & 17 & $0.0658 \pm \mathrm{j} 3.7896$ & -0.0017 \\
\hline 18 & 18 & $0.2012 \pm \mathrm{j} 4.3186$ & -0.3107 \\
\hline 19 & 19 & $0.4029 \pm \mathrm{j} 3.1139$ & -0.0108 \\
\hline 20 & 20 & $0.0079 \pm \mathrm{j} 2.0146$ & -0.2889 \\
\hline 21 & 21 & $-0.1176 \pm \mathrm{j} 3.1134$ & -0.4011 \\
\hline 22 & 22 & $0.2021 \pm \mathrm{j} 2.0343$ & -0.0003 \\
\hline 23 & 23 & $0.3964 \pm \mathrm{j} 4.1342$ & -0.2987 \\
\hline 24 & 24 & $0.0788 \pm \mathrm{j} 3.4342$ & -0.3421 \\
\hline 25 & 25 & $0.1865 \pm \mathrm{j} 4.0072$ & -0.0482 \\
\hline 26 & 26 & $0.2108 \pm 3.3319$ & -0.0569 \\
\hline 27 & 27 & $0.0984 \pm \mathrm{j} 2.7934$ & -0.1867 \\
\hline 28 & 28 & $0.3012 \pm \mathrm{j} 4.4310$ & -0.3065 \\
\hline 29 & 29 & $0.0567 \pm \mathrm{j} 4.0173$ & -0.0768 \\
\hline 30 & 30 & $0.1684 \pm \mathrm{j} 3.1605$ & -0.1347 \\
\hline 31 & 31 & $0.2123 \pm \mathrm{j} 5.0876$ & 0.3675 \\
\hline
\end{tabular}




\begin{tabular}{|c|c|c|c|}
\hline S/No. & Bus No. & Eigen value $(\lambda)$ & Damping Ratio $(\varsigma)$ \\
\hline 32 & 32 & $0.0478 \pm \mathrm{j} 3.0309$ & -0.2110 \\
\hline 33 & 33 & $0.5426 \pm \mathrm{j} 7.3025$ & 0.02137 \\
\hline 34 & 34 & $0.0647 \pm \mathrm{j} 3.2253$ & 0.0135 \\
\hline 35 & 35 & $0.0713 \pm \mathrm{j} 3.3427$ & -0.0424 \\
\hline 36 & 36 & $-0.7248 \pm \mathrm{j} 2.8783$ & 0.1135 \\
\hline 37 & 37 & $0.0014 \pm \mathrm{j} 2.5144$ & -0.0057 \\
\hline 38 & 38 & $0.1912 \pm \mathrm{j} 5.808$ & -0.0332 \\
\hline 39 & 39 & $-0.1953 \pm \mathrm{j} 5.716$ & -0.0348 \\
\hline 40 & 40 & $0.088 \pm \mathrm{j} 4.002$ & -0.022 \\
\hline 41 & 41 & $0.4302 \pm \mathrm{j} 3.6798$ & -0.3107 \\
\hline 42 & 42 & $0.0271 \pm \mathrm{j} 2.0154$ & -0.0313 \\
\hline 43 & 43 & $-0.1212 \pm \mathrm{j} 3.7982$ & -0.0324 \\
\hline 44 & 44 & $0.0753 \pm \mathrm{j} 3.3835$ & -0.0256 \\
\hline 45 & 45 & $0.0853 \pm \mathrm{j} 4.1012$ & -0.0227 \\
\hline 46 & 46 & $0.0335 \pm \mathrm{j} 6.852$ & -0.0015 \\
\hline 47 & 47 & $0.0658 \pm \mathrm{j} 3.7896$ & -0.0016 \\
\hline 48 & 48 & $0.3012 \pm \mathrm{j} 5.3186$ & -0.3089 \\
\hline
\end{tabular}

Table 5: Result of Power Flow Solution of the Case Study Power System Buses During the Outage of Transmission Line between Bus 31 and 29

\begin{tabular}{|c|c|c|c|c|}
\hline Bus\# & Voltage magnitude (P.u) & Voltage angle( rad ) & P(P.u) & Q(P.u) \\
\hline 1 & 0.7326 & -0.7817 & -0.5913 & -0.1086 \\
\hline 2 & 0.6979 & -0.5016 & -0.5344 & -0.1122 \\
\hline 3 & 0.9328 & -0.6943 & -0.7676 & -0.2697 \\
\hline 4 & 0.4513 & -0.7625 & -0.5347 & -0.0498 \\
\hline 5 & 1.1056 & -0.9227 & -0.4264 & -0.5617 \\
\hline 6 & 0.3696 & -0.3348 & -0.4128 & -0.9834 \\
\hline 7 & 0.4934 & -0.5812 & -0.4576 & -0.1307 \\
\hline 8 & 0.7579 & -0.3521 & -0.5504 & -0.1809 \\
\hline 9 & 1.2041 & -0.4817 & -0.5413 & -0.1086 \\
\hline 10 & 0.9873 & -0.4016 & -0.5644 & -0.1122 \\
\hline 11 & 0.3934 & -0.6243 & -0.7646 & -0.2607 \\
\hline 12 & 1.0034 & -0.4625 & -0.5347 & -0.0998 \\
\hline 13 & 0.4676 & -0.4227 & -0.4264 & -0.1017 \\
\hline 14 & 0.3696 & -0.3998 & -0.4128 & -0.1034 \\
\hline 15 & 0.4986 & -0.5012 & -0.4576 & -0.1507 \\
\hline 16 & 0.7579 & -0.4521 & -0.5504 & -0.1809 \\
\hline 17 & 0.6506 & -0.4332 & -0.4869 & -0.1264 \\
\hline 18 & 0.6347 & -0.3865 & -0.4337 & -0.1413 \\
\hline 19 & 0.9717 & -0.4386 & -0.5812 & -0.1118 \\
\hline 20 & 0.9681 & -0.3318 & -0.5795 & -0.0819 \\
\hline 21 & 0.8576 & -0.4626 & -0.4932 & -0.1338 \\
\hline 22 & 0.6792 & -0.3982 & -0.5216 & -0.2013 \\
\hline 23 & 0.4647 & -0.5984 & -0.6937 & -0.2446 \\
\hline 24 & 0.3120 & -0.3202 & -0.4827 & -0.1579 \\
\hline 25 & 0.4795 & -0.4529 & -0.4243 & -0.1834 \\
\hline 26 & 1.1052 & -0.4467 & -0.5006 & -0.1134 \\
\hline 27 & 0.5613 & -0.3846 & -0.5138 & -0.2007 \\
\hline 28 & 0.8819 & -0.4822 & -0.5623 & -0.1613 \\
\hline 29 & 0.4982 & -0.4116 & -0.4985 & -0.1517 \\
\hline 30 & 0.6813 & -0.3976 & -0.5963 & -0.1549 \\
\hline 31 & 0.9326 & -0.7817 & -0.5913 & -0.1086 \\
\hline 32 & 1.0120 & -0.5016 & -0.5344 & -0.1122 \\
\hline & & & & \\
\hline
\end{tabular}




\begin{tabular}{|c|c|c|c|c|}
\hline Bus\# & Voltage magnitude (P.u) & Voltage angle( rad ) & P(P.u) & Q(P.u) \\
\hline 33 & 0.9328 & -0.6943 & -0.7676 & -0.2697 \\
\hline 34 & 1.0123 & -0.7625 & -0.5347 & -0.0498 \\
\hline 35 & 1.0234 & -0.9227 & -0.4264 & -0.5617 \\
\hline 36 & 0.7696 & -0.3348 & -0.4128 & -0.9834 \\
\hline 37 & 0.8934 & -0.5812 & -0.4576 & -0.1307 \\
\hline 38 & 1.0325 & -0.3521 & -0.5504 & -0.1809 \\
\hline 39 & 0.5326 & -0.4817 & -0.5413 & -0.1086 \\
\hline 40 & 0.9579 & -0.4016 & -0.5644 & -0.1122 \\
\hline 41 & 0.3248 & -0.6243 & -0.7646 & -0.2607 \\
\hline 42 & 1.0045 & -0.4625 & -0.5347 & -0.0998 \\
\hline 43 & 0.8676 & -0.4227 & -0.4264 & -0.1017 \\
\hline 44 & 0.4696 & -0.3998 & -0.4128 & -0.1034 \\
\hline 45 & 0.8934 & -0.5012 & -0.4576 & -0.1507 \\
\hline 46 & 1.2067 & -0.4521 & -0.5504 & -0.1809 \\
\hline 47 & 0.9506 & -0.4332 & -0.4869 & -0.1264 \\
\hline 48 & 1.0453 & -0.3865 & -0.4337 & -0.1413 \\
\hline
\end{tabular}

The 330KV Simulink network was simulated without PSS for transmission line and power plant. The circuit breaker in the Simulink library was made to open and reclose the circuit of bus 31 and 29 in 1second after five cycles and Genetic Eigenvalue computation program was run during the simulation to compute the system eigenvalue, damping ratio and participation factor.The power flow program was activated to carry out power flow solution of the power system. The comparative analysis of the impact of contingencies on network without PSS as shown in table 4, all the real part of eigenvalues lie on the right half s-plane (all positive) - system unstable, damping ratios of eigenvalues are very small, bus 11 is most negative and most of the buses are below $5 \%$ and 0.2 damping threshold. Table 5shows that there is serious voltage degradation at the buses of the power system. The voltages in most of the buses are degraded. The exciters on the generators alone cannot stabilize the oscillation.

Table 6: Eigen values and damping ratios of the case study power system buses for the outage of generator 4.

\begin{tabular}{|c|c|c|c|}
\hline S/No. & Bus No. & Eigen value $(\lambda)$ & Damping Ratio( $(\varsigma)$ \\
\hline 1 & 1 & $0.4806 \pm \mathrm{j} 8.1476$ & -0.7627 \\
\hline 2 & 2 & $0.46302 \pm \mathrm{j} 6.7734$ & -0.37414 \\
\hline 3 & 3 & $0.4564 \pm \mathrm{j} 5.3247$ & -0.3867 \\
\hline 4 & 4 & $0.3206 \pm \mathrm{j} 8.1476$ & -0.3627 \\
\hline 5 & 5 & $0.4465 \pm \mathrm{j} 4.8942$ & -0.4019 \\
\hline 6 & 6 & $0.4947 \pm \mathrm{j} 4.4366$ & -0.39434 \\
\hline 7 & 7 & $0.5367 \pm \mathrm{j} 4.3008$ & -0.3762 \\
\hline 8 & 8 & $0.4823 \pm \mathrm{j} 5.1163$ & -0.4918 \\
\hline 9 & 9 & $0.6975 \pm \mathrm{j} 63465$ & -0.5328 \\
\hline 10 & 10 & $0.6732 \pm \mathrm{j} 6.2248$ & -0.5562 \\
\hline 11 & 11 & $0.7806 \pm \mathrm{j} 8.1476$ & -0.7627 \\
\hline 12 & 12 & $0.7453 \pm \mathrm{j} 7.9969$ & -0.6834 \\
\hline 13 & 13 & $0.7113 \pm \mathrm{j} 6.9937$ & -0.7234 \\
\hline 14 & 14 & $0.7734 \pm \mathrm{j} 7.93644$ & -0.7274 \\
\hline 15 & 15 & $0.6973 \pm \mathrm{j} 6.9347$ & -0.6348 \\
\hline 16 & 16 & $0.7389 \pm \mathrm{j} 6.3021$ & -0.6849 \\
\hline 17 & 17 & $0.7546 \pm \mathrm{j} 7.3489$ & -0.6805 \\
\hline 18 & 18 & $0.6874 \pm \mathrm{j} 6.6534$ & -0.5964 \\
\hline 19 & 19 & $0.5686 \pm \mathrm{j} 7.7347$ & -0.5004 \\
\hline 20 & 20 & $0.6896 \pm \mathrm{j} 6.7347$ & -0.4908 \\
\hline 21 & 21 & $0.7834 \pm \mathrm{j} 8.2236$ & -0.6618 \\
\hline 22 & 22 & $0.7263 \pm \mathrm{j} 7.7993$ & -0.6536 \\
\hline 23 & 23 & $0.7658 \pm \mathrm{j} 8.8463$ & -0.6889 \\
\hline 24 & 24 & $0.6835 \pm \mathrm{j} 8.0013$ & -0.5876 \\
\hline 25 & 25 & $0.5342 \pm \mathrm{j} 6.1136$ & -0.4546 \\
\hline 26 & 26 & $0.6423 \pm \mathrm{j} 5.8376$ & -0.4987 \\
\hline & & & \\
\hline
\end{tabular}




\begin{tabular}{|c|c|c|c|}
\hline S/No. & Bus No. & Eigen value $(\lambda)$ & Damping Ratio $(\varsigma)$ \\
\hline 27 & 27 & $0.7102 \pm \mathrm{j} 6.3476$ & -0.6482 \\
\hline 28 & 28 & $0.6659 \pm \mathrm{j} 5.3426$ & -0.5586 \\
\hline 29 & 29 & $0.7508 \pm \mathrm{j} 6.3246$ & -0.6863 \\
\hline 30 & 30 & $0.7302 \pm \mathrm{j} 7.0034$ & -0.6537 \\
\hline 31 & 31 & $0.4706 \pm \mathrm{j} 8.1476$ & -0.5627 \\
\hline 32 & 32 & $0.36302 \pm \mathrm{j} 6.7734$ & -0.37414 \\
\hline 33 & 33 & $0.4564 \pm \mathrm{j} 5.3247$ & -0.3867 \\
\hline 34 & 34 & $0.3206 \pm \mathrm{j} 8.1476$ & -0.1627 \\
\hline 35 & 35 & $0.4465 \pm \mathrm{j} 4.8942$ & -0.4019 \\
\hline 36 & 36 & $0.6947 \pm \mathrm{j} 4.4366$ & -0.39434 \\
\hline 37 & 37 & $0.5367 \pm \mathrm{j} 4.3008$ & -0.3762 \\
\hline 38 & 38 & $0.4823 \pm \mathrm{j} 5.1163$ & -0.6918 \\
\hline 39 & 39 & $0.3975 \pm \mathrm{j} 63465$ & -0.5328 \\
\hline 40 & 40 & $0.6732 \pm \mathrm{j} 6.2248$ & -0.5562 \\
\hline 41 & 41 & $0.7806 \pm \mathrm{j} 8.1476$ & -0.7627 \\
\hline 42 & 42 & $0.6353 \pm \mathrm{j} 7.9969$ & -0.6834 \\
\hline 43 & 43 & $0.6813 \pm \mathrm{j} 6.9937$ & -0.7634 \\
\hline 44 & 44 & $0.2434 \pm \mathrm{j} 7.93644$ & -0.2274 \\
\hline 45 & 45 & $0.5973 \pm \mathrm{j} 6.9347$ & -0.6348 \\
\hline 46 & 46 & $0.8389 \pm \mathrm{j} 6.3021$ & -0.4849 \\
\hline 47 & 47 & $0.2946 \pm \mathrm{j} 7.3489$ & -0.9805 \\
\hline 48 & 48 & $0.5174 \pm \mathrm{j} 6.6534$ & -0.2964 \\
\hline
\end{tabular}

Table 7: Result of Power flow Solution of Case Study Power System for The Outage of Generator 4 without Stabilizer

\begin{tabular}{|c|c|c|c|c|}
\hline Bus\# & Voltage magnitude (P.u) & $\begin{array}{l}\text { Voltage angle } \\
\text { ( rad ) }\end{array}$ & P(P.u) & $\mathrm{Q}(\mathrm{P} . \mathrm{u})$ \\
\hline 1 & 0.5427 & -0.7423 & -0.8347 & -0.1579 \\
\hline 2 & 0.4012 & -0.5276 & -0.9809 & -0.1834 \\
\hline 3 & 0.5867 & -0.9043 & -0.7643 & -0.1134 \\
\hline 4 & 0.4216 & -0.5646 & -0.6217 & -0.2007 \\
\hline 5 & 1.002 & -0.5267 & -0.5784 & -0.1613 \\
\hline 6 & 0.7017 & -0.4896 & -0.5629 & -0.1517 \\
\hline 7 & 0.1987 & -0.6876 & -0.6243 & -0.1549 \\
\hline 8 & 0.1996 & -0.6248 & -0.6543 & -0.1086 \\
\hline 9 & 1.0231 & -0.6423 & -0.6347 & -0.1122 \\
\hline 10 & 1.0012 & -0.5836 & -0.9809 & -0.2697 \\
\hline 11 & 0.2342 & -0.8643 & -0.7643 & -0.0498 \\
\hline 12 & 0.9978 & -0.5646 & -0.6217 & -0.5617 \\
\hline 13 & 0.2213 & -0.5967 & -0.5784 & -0.9834 \\
\hline 14 & 0.3017 & -0.4896 & -0.5629 & -0.1307 \\
\hline 15 & 0.3987 & -0.6876 & -0.6243 & -0.1809 \\
\hline 16 & 0.7996 & -0.6248 & -0.6543 & -0.1086 \\
\hline 17 & 0.2003 & -0.6024 & -0.5567 & -0.1122 \\
\hline 18 & 0.6876 & -0.4567 & -0.5243 & -0.2607 \\
\hline 19 & 0.9226 & -0.6132 & -0.6617 & -0.0998 \\
\hline 20 & 0.3672 & -0.4342 & -0.6834 & -0.1017 \\
\hline 21 & 0.3214 & -0.6182 & -0.6324 & -0.1034 \\
\hline 22 & 0.7186 & -0.4644 & -0.6685 & -0.1507 \\
\hline 23 & 0.3987 & -0.8835 & -0.7408 & -0.1809 \\
\hline 24 & 0.4236 & -0.4263 & -0.6847 & -0.1264 \\
\hline 25 & 0.8106 & -0.6124 & -0.5246 & -0.1413 \\
\hline 26 & 0.3242 & -0.6245 & -0.6534 & -0.1086 \\
\hline 27 & 0.3743 & -0.4168 & -0.5965 & -0.1122 \\
\hline 28 & 0.5206 & -0.6428 & -0.6703 & -0.2697 \\
\hline 29 & 0.2459 & -0.5986 & -0.6136 & -0.0498 \\
\hline
\end{tabular}




\begin{tabular}{|c|c|c|c|c|}
\hline Bus\# & Voltage magnitude (P.u) & $\begin{array}{c}\text { Voltage angle } \\
(\text { rad })\end{array}$ & P(P.u) & Q(P.u) \\
\hline 30 & 0.3842 & -0.4857 & -0.6889 & -0.5617 \\
\hline 31 & 0.5427 & -0.7423 & -0.8347 & -0.9834 \\
\hline 32 & 0.2012 & -0.5276 & -0.9809 & -0.1307 \\
\hline 33 & 0.1867 & -0.9043 & -0.7643 & -0.1809 \\
\hline 34 & 1.0342 & -0.5246 & -0.6217 & -0.1086 \\
\hline 35 & 1.1056 & -0.5267 & -0.5784 & -0.1122 \\
\hline 36 & 0.7017 & -0.4896 & -0.5629 & -0.2607 \\
\hline 37 & 0.1987 & -0.6976 & -0.6243 & -0.0998 \\
\hline 38 & 1.1996 & -0.6248 & -0.6543 & -0.1017 \\
\hline 39 & 0.3427 & -0.6123 & -0.6347 & -0.1034 \\
\hline 40 & 0.2012 & -0.5436 & -0.9809 & -0.1507 \\
\hline 41 & 0.1867 & -0.8643 & -0.7643 & -0.1809 \\
\hline 42 & 1.0342 & -0.5646 & -0.6217 & -0.1264 \\
\hline 43 & 0.4213 & -0.5967 & -0.5784 & -0.1413 \\
\hline 44 & 0.3017 & -0.4896 & -0.5629 & -0.1118 \\
\hline 45 & 0.2987 & -0.6876 & -0.6243 & -0.0819 \\
\hline 46 & 1.1906 & -0.6248 & -0.6543 & -0.1338 \\
\hline 47 & 0.2003 & -0.6024 & -0.5567 & -0.2013 \\
\hline 48 & 0.2876 & -0.4567 & -0.5243 & -0.2446 \\
\hline
\end{tabular}

Table 7 gives the output of the power flow solution carried out by $\boldsymbol{P}$-flow using the generator outage disturbance data.

The result in this table shows that Voltage magnitude indicates serious degradation in the bus voltage. The degradation in table 7 is higher than that of 5 showing more voltage degradation severity

From table 6 the transmission line outage contingency, the voltage of bus 11 stood at 0.3934 p.u, that of bus 15 stood at 0.4986 p.u and that of bus 23 stood at 0.4647

From table 7 , for power plant outage, the voltage of bus 11 stood at 0.2342 p.u that of bus 15 stood at $0.3987 \mathrm{p} . \mathrm{u}$ while that of bus 23 stood at 0.3987 p.u. The real parts of the eigenvalue in table 5 are very much positive than the real parts of the eigenvalues in table 4 .

The voltage trajectories of the power system case study buses were compared from without PSS, and with PSS using Genetic and Arnoldi stability analysis technique as shown in figures 5-13

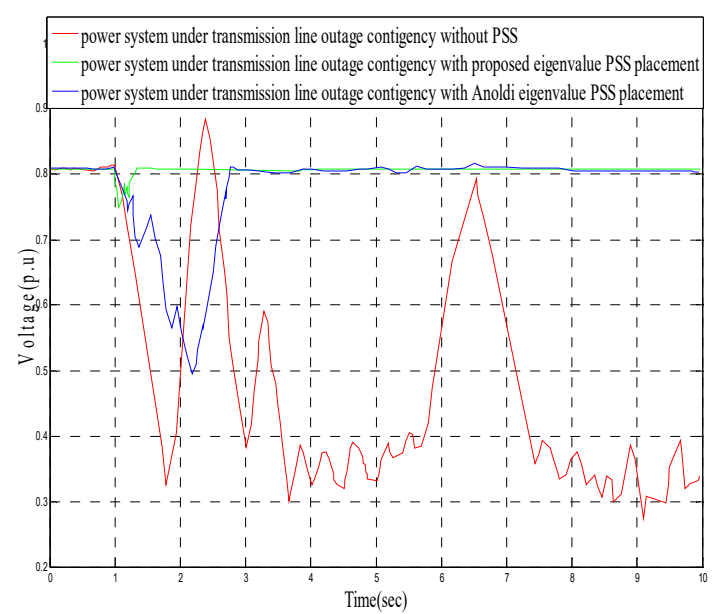

Figure: 5. Comparison of Voltage Trajectory at Bus 11 during Transmission Line Outage Contingency 


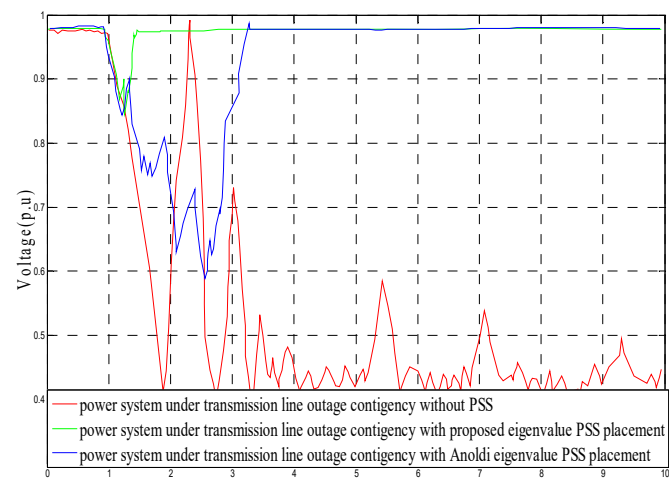

Time(sec)
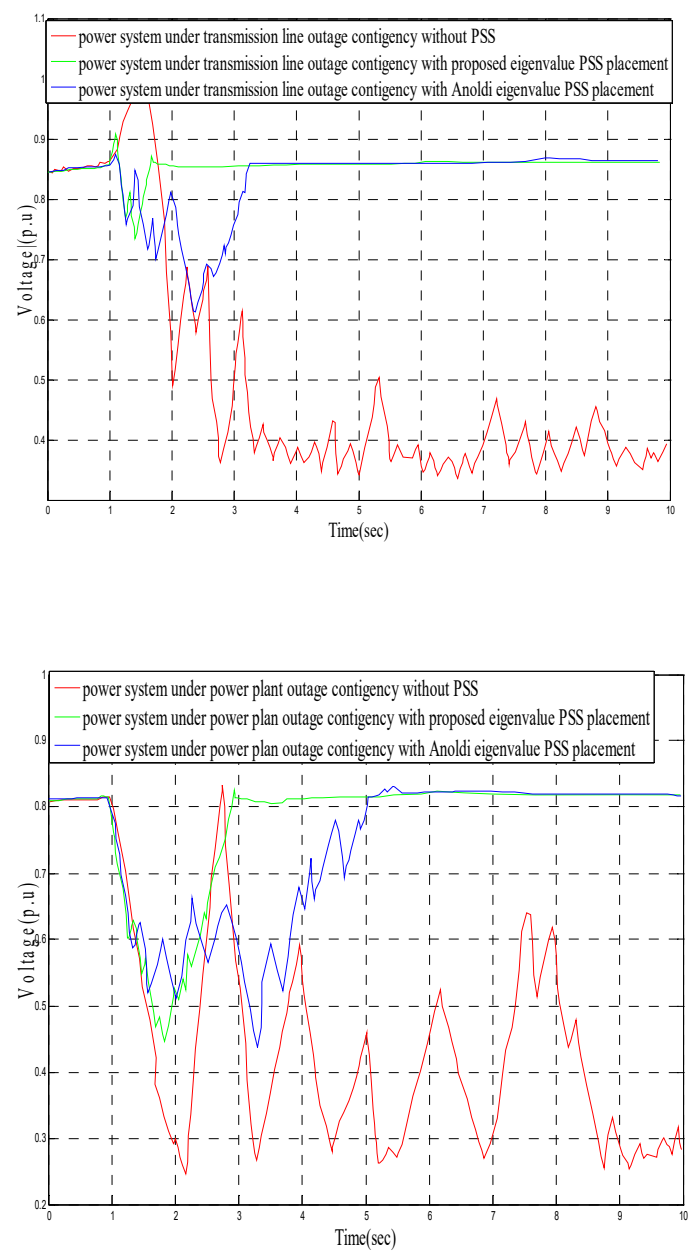

Figure 6. Comparison of Voltage Trajectory at Bus 15 during Transmission Line Outage Contingency

Figure 7:Comparison of Voltage Trajectory at Bus 23 duringTransmission Line Outage

Figure. 8: Comparison of Voltage Trajectory at Bus 11 during Power Plant Outage Contingency 

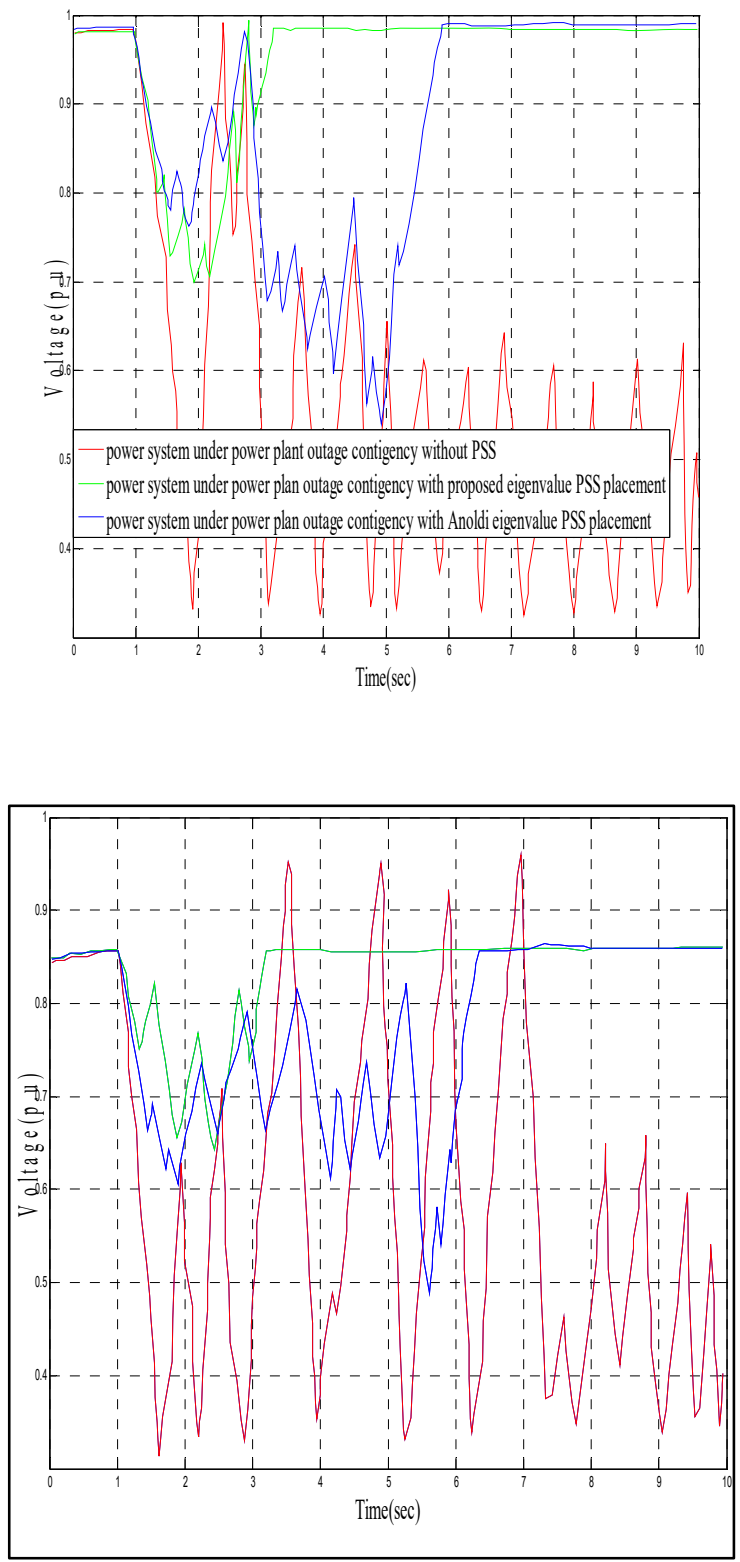

Figure 9: Comparison of Voltage Trajectory at Bus 15 during Power Plant Outage Contingency
Figure 10: Comparison of Voltage Trajectory at Bus 23 during Power Plant Outage Contingency 

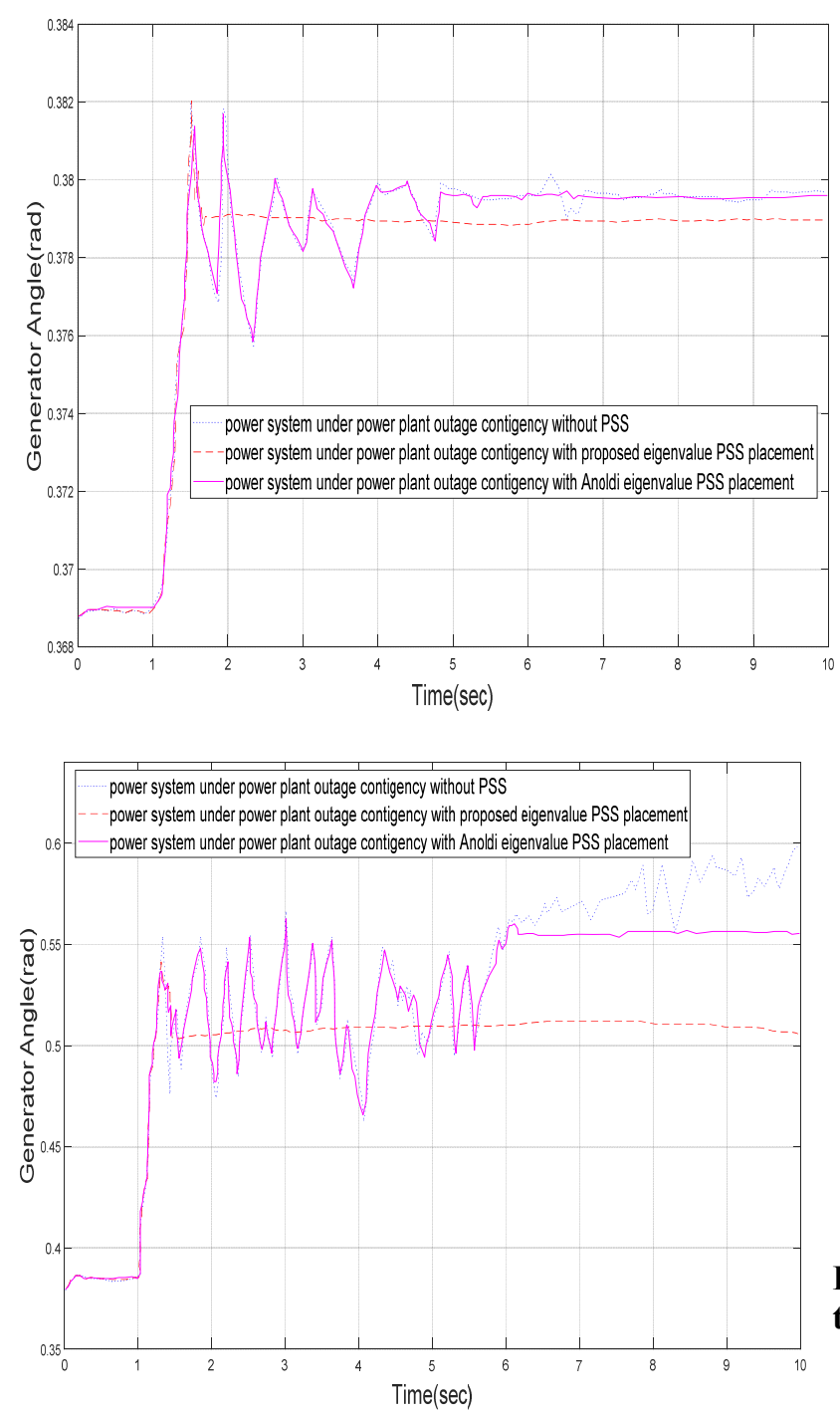

Figure 12: Comparison of generator 3 angle trajectory during power plant outage contingency

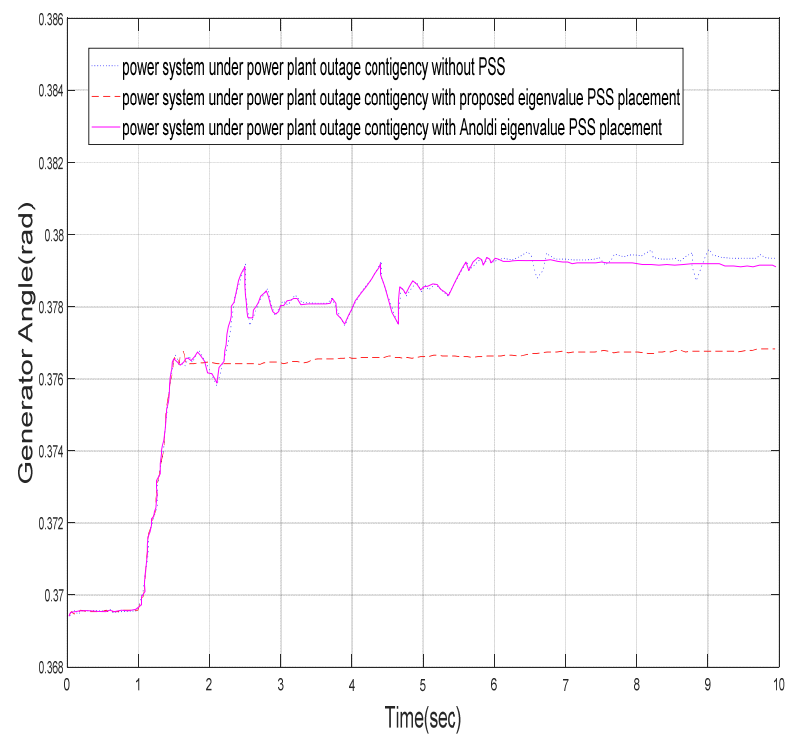

Figure 13: Comparison of generator 5 angle trajectory during power plant outage contingency 


\section{Confirmatory Evaluation of Power System Stabilization on an Interconnected Power System}

Figures 5 - 13showed comparative output trajectory of simulations with and without stabilizers installed under transmission line outage contingency and power plant outage contingencies using Genetic Eigenvalue stability technique and conventional Arnoldi Eigenvalue stability technique for placement of power system stabilizers at buses 11,15 and 23 for damping out oscillations

- At Bus 11,Genetic technique of placing PSS damped out voltage oscillations in 1.3458 secs Arnoldi technique of placing PSS damped out voltage oscillations in 2.772 secs

- At Bus 15,Genetic technique of placing PSS damped out voltage oscillations in 1.446 secs Arnoldi technique of placing PSS damped out voltage oscillations in 2.3.2712 secs

- At Bus 23Genetic technique of placing PSS damped out voltage oscillations in 1.6784secs. Arnoldi technique of placing PSS damped out voltage oscillations in $\mathbf{3 . 2 4 0 9}$ secs. \% of voltage instability suppression time improvement of Genetic Eigenvalue technique Arnoldi $=51.86 \%$

- At generator 1, \% load angle suppression time improvement for power plant outage contingency of Genetic Eigenvalue technique over Arnoldi $=74 \%$

- At generator 3, \% load angle suppression time improvement for power plant outage contingency of Genetic Eigenvalue technique over Arnoldi $=79 \%$

- At generator 5, \% load angle suppression time improvement for power plant outage contingency of Genetic Eigenvalue technique over Arnoldi $=76.98 \%$

\section{0 conclusion}

At this stage it is important to show the gain of power system stability of 330KV bus transmission line Grid network as well as the milestones achieved in this research. Apart from the over re-occurring benefit of improvement in Transmission Company of Nigeria and cost effectiveness, this work has led to the appreciation of somewhat power system Genetic Eigenvalue technique. The technique is unique and has proved quite handy in solving problems from load loss, equipment malfunctioning and unnecessary tripping arising from system contingencies in power plant and transmission lines. Having tested this technique personally, it is clear that the contingencies in power plant and transmission lines in National grid can be reduced drastically.

\section{Reference}

1.Abdalla O. A., Hassan S. A., and Tweig N. T., "Coordinated stabilization of a multimachine power system," IEEE Transactions on Power Apparatus and Systems, vol. PAS-103, no. 3, pp. 483-494, 2014.

2.Arcidiacono V, Ferrari E., R. Marconato R, Ghali J. D, and D. Grandez D., "Evaluation and improvement of electromechanical oscillation damping by means of eigenvalueeigenvector analysis. Practical results in the central Peru power system," IEEE Transactions on Power Apparatus and Systems, vol. PAS-99, no. 2, pp. 769-778, 2017

3.Doi .A \& Abe S., "Coordinated synthesis of power system stabilizers in multimachine power systems", IEEE Transactions on Power Apparatus and Systems, vol. PAS-103, no. 6, pp. 1473-1479, 2017.

4.Fretwell A, Tanaka S Lam D.M, Yu C.Y, M. Shimomura,., Itoh M, "Design, installation and operation of power system stabilizers on the Hong Kong electric power system”, in International Conference on Advances in Power System Control, Operationand Management (APSCOM-91), 1991, pp. 534-541, vol. 2, 1991.

5.Kundur P, “A survey of utility experiences with power plant response during partial load rejections and system disturbances," IEEE Trans.Power Apparatus and Systems, vol. PAS-100, pp. 2471-2475, 2010,

6.Li Wu; Wang Zhixin; "A Basic Study of Fuzzy-Logic-Based Power System Stabilization with Doubly-Fed Asynchronous Machine”, CES/IEEE 5th International Power Electronics and Motion Control Conference (IPEMC), Vol. 3, Pp. 1-5, 2016.

7. Lu J, Chiang H.D, and Thorp J.S., Identification of optimum sites for power system stabilizer applications, IEEE Transactions on Power Systems, vol. 5, no. 4, pp. 1302- 1308.(2002),

8. Martins N and L. T. G. Lima, "Determination of suitable locations for power system stabilizers and static VAR compensators for damping electromechanical oscillations in large scale power systems," IEEE Transactions on Power Systems, vol. 5, no. 4, pp. 1455-1469, 1990.

9.NESS J. Van, J. Boyle \& F. Imad (2015), Sensitivities of large, multiple-loop control systems, IEEE Transactions on Automatic Control, vol. 10, no. 3, pp. 308-315, 2015.

10.Ostojic D.R., "Identification of optimum site for power system stabiliser applications," IEE ProceedingsGeneration, Transmission, and Distribution, vol. 135, no. 5, pp. 416- 419, 2008.

11.Ostojic D. R. \&Heydt G.T, "Transient stability assessment by pattern recognition in the frequency domain, IEEE Transactions on Power Systems", vol. 6, no. 1, pp. 231-237, 2019, 